\title{
Uptake of exogenous DNA by mammalian spermatozoa: specific localization of DNA on sperm heads
}

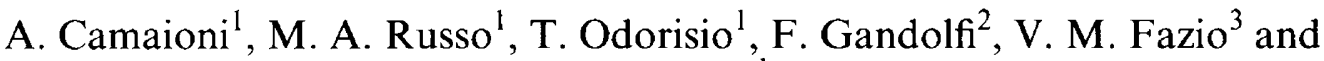 \\ G. Siracusa ${ }^{1}$ \\ ${ }^{\prime}$ Department of Public Health and Cell Biology, II University of Rome, I-00173, Rome, Italy; \\ ${ }^{2}$ Institute of Anatomy of Domestic Animals, University of Milan, Italy; and ${ }^{3} \mathrm{CNR}$ Institute of \\ Experimental Medicine, Rome, Italy
}

\begin{abstract}
Summary. When mouse spermatozoa were briefly exposed in culture to radioactively labelled DNA (pSV2CAT plasmid), radioactivity could be detected by high-resolution autoradiography on the surface and within the nucleus of the spermatozoa. Spermatozoa from other mammalian species (boar, bull, man) could also bind foreign DNA. With the exclusion of human spermatozoa, which in most experiments showed very low labelling values, labelling percentages (evaluated by light microscope autoradiography) ranged between 39 and $78 \%$. In all four species the DNA-binding ability was mainly confined to a specific region of the sperm head (equatorial segment and postacrosomal region), and the sperm-DNA association kinetics were rapid (maximum values were reached within 20-40 $\mathrm{min}$ ). The data also indicate that factor(s) in seminal plasma might protect spermatozoa from accidental transfection by foreign DNA that may be present in the genital tracts from bacterial or viral sources.
\end{abstract}

Keywords: spermatozoa; DNA; heparin; transfection; transgenic animals

\section{Introduction}

The genotype of mammalian and other eukaryotic cells can be experimentally altered in vitro by a simple procedure similar to that used by Avery et al. (1944) in their classic bacterial transformation experiments: when purified DNA is added to a culture of eukaryotic cells, such cells occasionally take up the DNA, integrate it into their genome, express it and transmit it to their progeny, thus creating new stable lines (Pellicer et al., 1980). Unless particular experimental devices (such as electroporation and coprecipitation of DNA with calcium phosphate) are used, the transfecting efficiency of the system is quite low (of the order of $1: 10^{6}$ exposed cells). Rabbit and mouse spermatozoa, in contrast, appear to have a spontaneous tendency to take up exogenous DNA molecules present in the culture medium. Cultured rabbit spermatozoa incorporated SV40 DNA, which was transferred to eggs at fertilization, as shown by recovery of viral activity from resulting early embryos (Brackett et al., 1971). When mouse spermatozoa are briefly cultured in the presence of recombinant radioactive $\mathrm{pSV} 2 \mathrm{CAT}$ plasmid, they rapidly take up radioactivity from the culture medium; after in vitro fertilization, such spermatozoa can generate transgenic mice which stably integrate the foreign DNA sequences in their genomes and may express the chloramphenicol acetyl transferase $(C A T)$ gene (Lavitrano et al., 1989). Although various workers have failed to replicate these experiments (Brinster et al., 1989), exogenous DNA has been detected in mouse and cattle blastocysts (Hochi et al., 1990; Perez et al., 1991), sea urchin blastulae (Arezzo, 1989) and adult pigs (Gandolfi et al., 1989), all originating from spermatozoa that had been exposed to foreign DNA.

In the present study, we characterized by autoradiographic analysis the unusual DNA-binding ability shown by mouse spermatozoa by answering the following questions. Is there a specialized 
DNA-binding region on the spermatozoa? Is bound DNA transferred from the sperm surface to the sperm nucleus? Is the ability to bind DNA shown by rabbit and mouse spermatozoa also present in spermatozoa from other mammalian species (boar, bull, man)? What are the kinetics of such phenomena? Are there, in the seminal plasma, factor(s) that might protect such mammalian spermatozoa from taking up exogenous DNA?

\section{Materials and Methods}

\section{Spermatozoa}

Epididymal spermatozoa were obtained from the cauda epididymidis of CD1 mice (purchased from Charles River, Como, Italy), as described by Lavitrano et al. (1989). Ejaculated mouse semen was recovered from the uterus of superovulated female mice within 15 min of mating, as described by Whittingham (1968).

Ejaculated human spermatozoa were obtained from healthy young donors. Highly motile spermatozoa were collected by the swim-up procedure (Braude, 1987). In experiments in which spermatozoa were to be extensively washed, this was done by suspending $1 \mathrm{ml}$ of semen in $50 \mathrm{ml}$ of medium and centrifuging for $10 \mathrm{~min}$ at $200 \mathrm{~g}$. The pellet was resuspended in $50 \mathrm{ml}$ of medium and centrifuged twice more.

Cryopreserved samples of bovine spermatozoa were obtained from Associazione Romana Allevatori (Rome, Italy), packaged in $0.2 \mathrm{ml}$ French straws. The straws were thawed by immersion in a $37^{\circ} \mathrm{C}$ water bath for $1 \mathrm{~min}$, the semen sample was suspended in $10 \mathrm{ml}$ of culture medium and washed twice by centrifugation $(275 \mathrm{~g}, 10 \mathrm{~min})$ and pellet resuspension in $10 \mathrm{ml}$ of fresh medium.

Aliquots of ejaculated boar spermatozoa (sperm-rich fraction) were immediately diluted 1:2 with culture medium and washed three times by centrifugation $(350 \mathrm{~g}, 10 \mathrm{~min})$ and resuspension of the sperm pellet in $10 \mathrm{ml}$ of fresh medium.

For all species, after the final centrifugation, the cells were resuspended in a small volume of culture medium and their concentration was evaluated by haemocytometer counting. Sperm motility was usually $>65 \%$. The spermatozoa were finally diluted to a concentration of $10^{7} \mathrm{ml}{ }^{1}$ and, after addition of labelled DNA, were cultured at $37^{\circ} \mathrm{C}$ in $5 \% \mathrm{CO}_{2}$.

In some experiments, the effect of incomplete removal of seminal plasma on labelled DNA binding by mouse ejaculated spermatozoa was tested. Ejaculates from two different mice were pooled, diluted 1:20 with culture medium and split into two parts. One part was centrifuged $(500 \mathrm{~g}, 10 \mathrm{~min})$ and all but about $0.5 \mathrm{ml}$ of the supernatant was removed. The pellet was resuspended and sperm concentration was evaluated and adjusted to $10^{7} \mathrm{ml}^{-1}$ by addition of the supernatant medium. The other part was washed three times by centrifugation and resuspension of the pellet in $10 \mathrm{ml}$ of fresh medium.

\section{Culture media}

Spermatozoa were collected, washed and cultured in the following media. Mouse spermatozoa: the modified Tyrode's solution (FM medium) described in Lavitrano et al. (1989) was used. The composition of FM medium is $120 \mathrm{mmol} \mathrm{NaCl} 1^{-1}, 2.68 \mathrm{mmol} \mathrm{KCl}^{-1}, 0.15 \mathrm{mmol} \mathrm{Na}_{2} \mathrm{HPO}_{4} 1^{-1}, 1.8 \mathrm{mmol} \mathrm{CaCl} \mathrm{L}^{-1}, 0.49 \mathrm{mmol} \mathrm{MgCl} \mathrm{I}^{-1}, 25 \mathrm{mmol}$

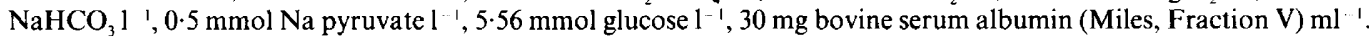
Earle's medium, prepared according to Braude (1987), was used for human spermatozoa; antibiotics were omitted. A modified Tyrode's solution (Sp-TALP, Parrish et al., 1988) was used for boar and bull spermatozoa; antibiotics were omitted.

\section{DNA}

For light and electron microscope autoradiography, spermatozoa were exposed for $1 \mathrm{~h}$ to ${ }^{3} \mathrm{H}$-nick-translated pSV2CAT DNA (5-15 $\times 10^{6}$ c.p.m. $\left.\mu \mathrm{g}^{-}{ }^{-} \mathrm{DNA}\right)$, that had been added to culture medium at $300 \mathrm{ng}$ DNA per million spermatozoa.

For uptake measurements, ${ }^{32} \mathrm{P}$-nick-translated DNA $\left(100-140 \times 10^{6} \mathrm{c} . \mathrm{p} . \mathrm{m} . \mu \mathrm{g}^{-1} \mathrm{DNA}\right)$ was added at $5 \mathrm{ng}$ per million spermatozoa.

\section{Autoradiography}

For light microscope autoradiography, $\left[{ }^{3} \mathrm{H}\right] \mathrm{DNA}$-labelled sperm suspensions were washed by four centrifugation and resuspension cycles to remove unbound DNA, smeared on gelatin-coated slides, dried at room temperature, gently and briefly washed with distilled water to remove salt crystals and fixed in ethanol and ethyl ether (1:1) for $30 \mathrm{~min}$. Preparations were coated with Ilford K2 emulsion, exposed for 3-4 days and processed by standard procedures (Rogers, 1973). At least 500 spermatozoa were microscopically analysed for evaluation of labelling percentage in each of two experiments. 
High-resolution autoradiography was performed essentially as described by Caro et al. (1962). Labelled sperm suspensions were washed as above, pelletted, fixed by glutaraldehyde and osmium tetroxide and embedded in epoxy resin (EPON 812). Ilford L4 emulsion was applied by the loop method over ultrathin sections previously mounted on Formvar-coated grids. After exposure for 4 weeks at $4^{\circ} \mathrm{C}$, the autoradiographs were developed by Microdol-X (Kodak), fixed and stained with lead citrate before examination.

\section{Spermatozoa- $-{ }^{32} \mathbf{P}[\mathrm{DNA}]$ association kinetics}

After incubation for various times in the presence of ${ }^{32} \mathrm{P}[\mathrm{DNA}]$, samples containing about $10^{6}$ spermatozoa were washed by centrifugation $(9000 \mathrm{~g}, 3 \mathrm{~min})$ and resuspension in fresh medium, and collected by vacuum filtration onto Millipore Durapore hydrophilic filters. The filters were then sequentially washed through with culture medium, distilled water and ethanol and ethyl ether $(1: 1)$ and radioactivity was measured in a scintillation counter. In the experiments with heparin, each sample $\left(10^{6}\right.$ spermatozoa) was pre-incubated for $30 \mathrm{~min}\left(37^{\circ} \mathrm{C}, 5 \% \mathrm{CO}_{2}\right)$ in medium containing various heparin concentrations before addition of labelled DNA and further incubation for $30 \mathrm{~min}$. The washing procedure was the same as described above.

\section{Results}

\section{Localization of DNA-binding regions on mammalian spermatozoa}

Thoroughly washed ejaculated spermatozoa from the four species examined and epididymal mouse spermatozoa displayed unequivocal autoradiographic labelling after exposure to tritiated, nick-translated pSV2CAT DNA ( $\left.{ }^{3} \mathrm{H}[\mathrm{DNA}]\right)$. No differences in labelling pattern were seen between ejaculated and epididymal mouse spermatozoa. Labelling was clearly restricted in all species to limited portions of the sperm head. In mice (Fig. la) the equatorial segment and the postacrosomal region were the areas where autoradiographic grains could be detected most commonly. In a minority of labelled cells, a few additional grains were often present on the foremost part of the cell (the apical segment of the acrosome) (Fig. 1a). Nearly identical labelling patterns were observed in bovine spermatozoa, from a few autoradiographic grains on the equatorial segment to a fully labelled postacrosomal region, with occasional apical labelling (Fig. 1b). The postacrosomal region was also clearly labelled in porcine (Fig. 1c) and human spermatozoa. In human cells, the labelled area generally extended beyond the small postacrosomal segment, to cover the connecting piece (Fig. 1d).

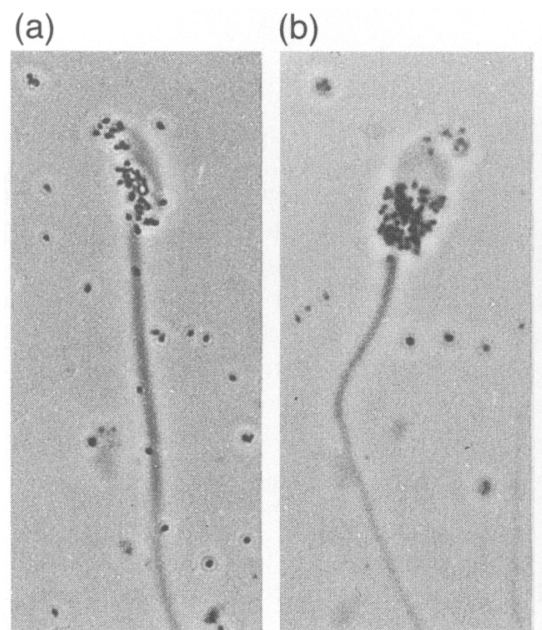

(c)

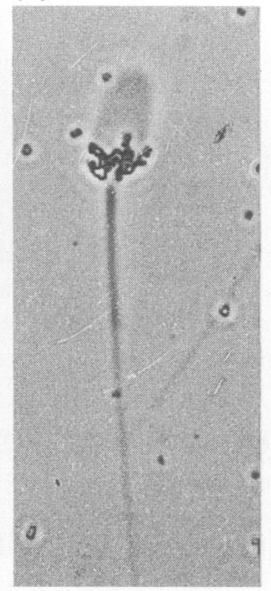

(d)

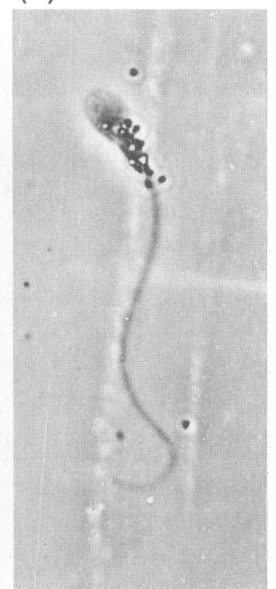

Fig. 1. Autoradiographs of ejaculated spermatozoa of (a) mouse, (b) bull, (c) boar and (d) human exposed to tritiated pSV2CAT DNA, showing the characteristic label distribution in each species. In all cells, silver grains reside over the equatorial segment and the postacrosomal region of the head. In human spermatozoa, the radioactivity also extends to cover the connecting piece (d). In a minority of cells, a few grains were also present on the foremost part of the cell ( $a$ and $b)$. Phase-contrast microscopy, $\times 1400$. 
(a)

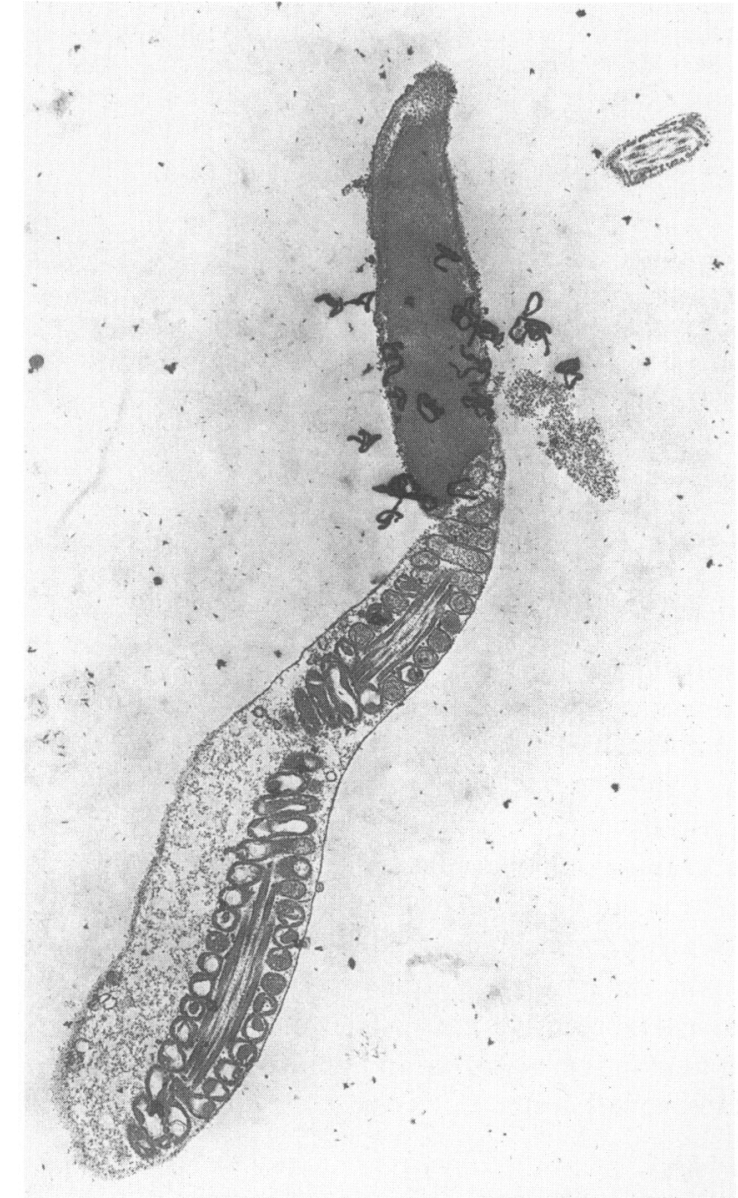

(b)

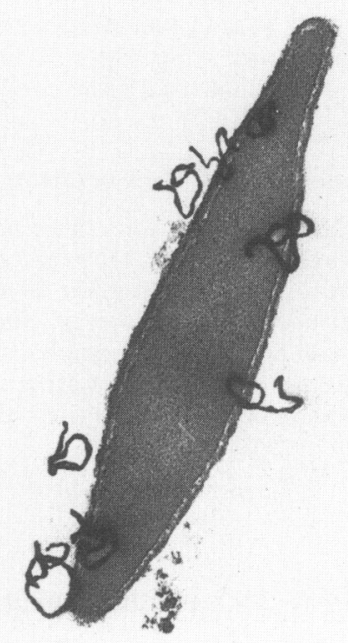

(c)

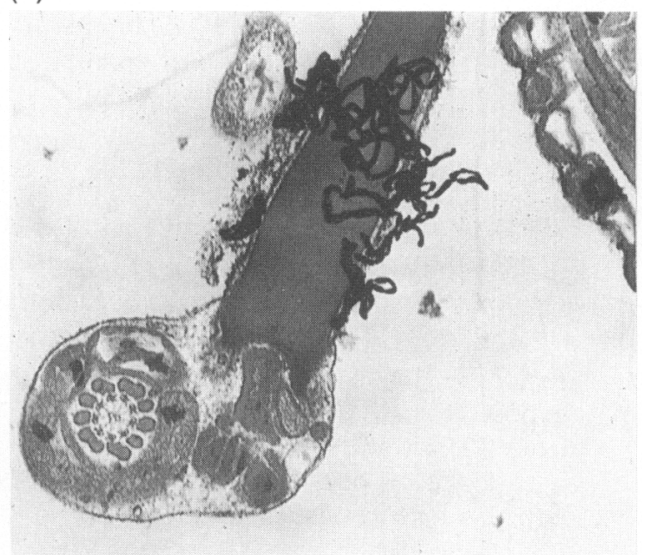

Fig. 2. Electron microscope autoradiographs, showing typical labelling patterns of mouse epididymal spermatozoa exposed to ${ }^{3} \mathrm{H}$ [DNA]. Radioactivity lies mainly over the distal part of the sperm head $(a, \times 9900)$. Silver grains are in most cases concentrated at the periphery of the cell $(b, \times 18000)$ and it was not established whether they were due to surface or intracellular radioactivity. In a few cells, numerous silver grains were also detected over the nuclear regions (c, $\times 20700$ ). No radioactivity was associated with the sperm tails (a).

\section{Localization of ${ }^{3} \mathrm{H}[\mathrm{DNA}]$ in mouse spermatozoa by high-resolution electron microscope autoradiography}

A series of electron micrographs of 88 labelled cells was studied to evaluate the subcellular localization of autoradiographic grains over transverse and longitudinal sections of epididymal mouse spermatozoa. In agreement with the observations made by light-microscope autoradiography, in all labelled cells the grains were mainly confined to the caudal part of the sperm head (Fig. 2a). In most cases, the grains were lying at the periphery of the cell (Fig. 2b) and it could not be established whether they arose from the plasma membrane only, or from the subjacent thin cytoplasmic layer as well. In general, grains were more frequent over the equatorial segment and 
(a)

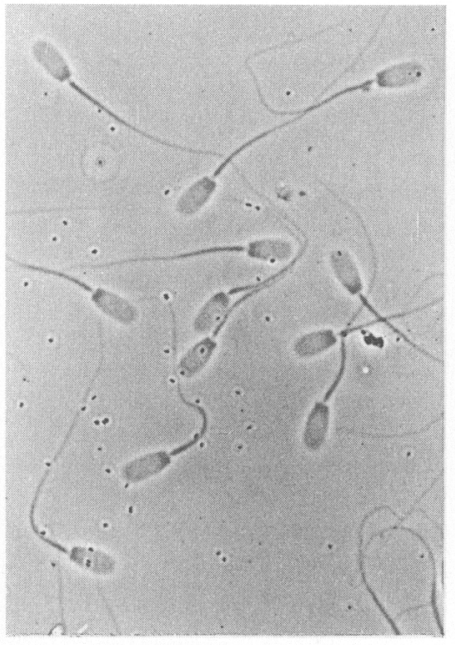

(d) (b)

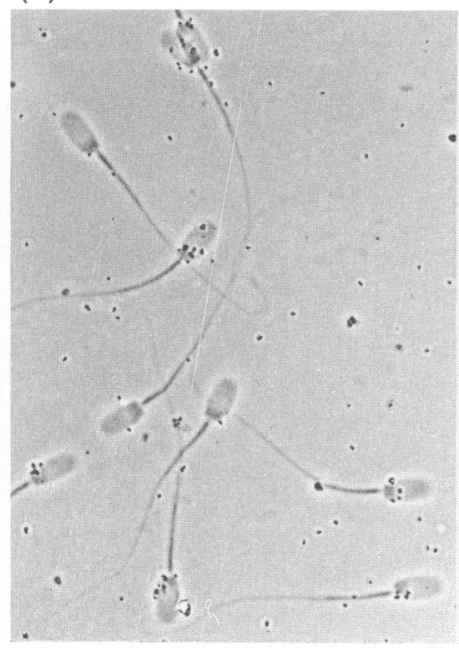

(e) (c)

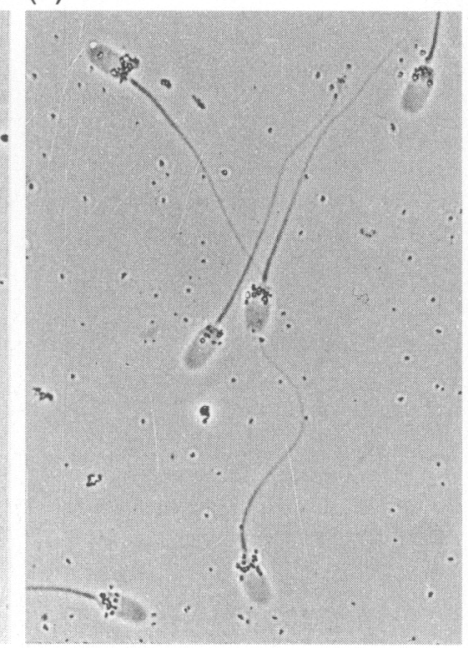

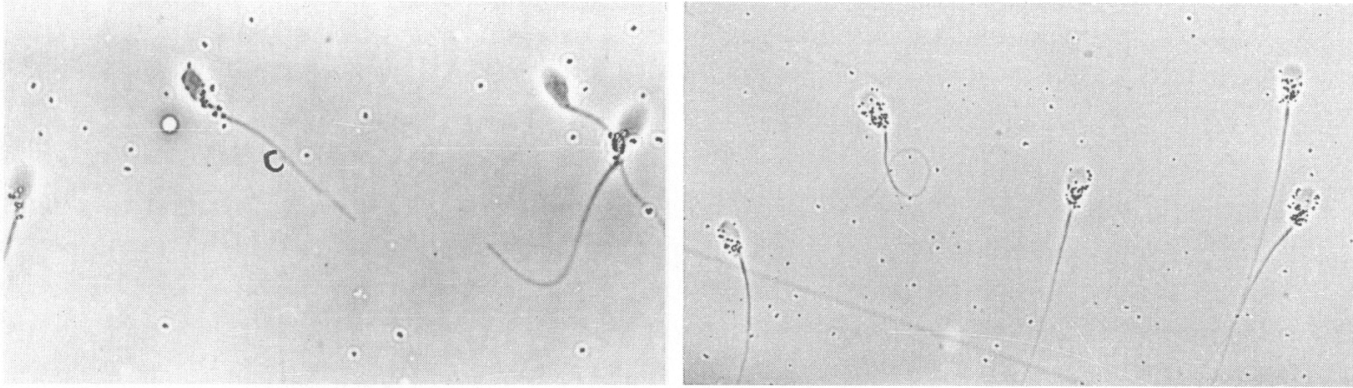

Fig. 3. Autoradiographs of ejaculated spermatozoa of $(\mathrm{a}-\mathrm{c})$ boar, (d) human and (e) bull exposed to ${ }^{3} \mathrm{H}[\mathrm{DNA}]$. Label is clearly associated with the heads of spermatozoa that have been extensively washed before exposure to ${ }^{3} \mathrm{H}[\mathrm{DNA}](\mathrm{c}, \mathrm{d}$ and e). Labelling intensity and percentage of labelled cells increased with the thoroughness of washing $(\mathrm{a}-\mathrm{c})$. Essentially no label was detected on boar spermatozoa exposed to ${ }^{3} \mathrm{H}[\mathrm{DNA}]$ in the presence of residual seminal plasma (a), but cell labelling progressively increased after two (b) or three (c) washing cycles. (a, b and c) $\times 620$, (d) $\times 800$, (e) $\times 530$.

less frequent towards the distal end of the sperm head (Fig. 2a and c). Autoradiographic grains were occasionally seen lying over the apical region of the acrosome (not shown). In about $10 \%$ of the labelled cells examined (10/88), numerous silver grains were clearly localized over the sperm nucleus (Fig. 2c); no label was seen over the sperm tails (Fig. 2a).

\section{Percentages of labelled spermatozoa and differences between ejaculated and epididymal spermatozoa}

In initial experiments with ejaculated boar and human spermatozoa, we were unable to detect autoradiographic labelling consistently (1:100-1:1000 labelled cells) after exposure of cells to tritiated DNA under the same experimental conditions that had generated high percentages of clearly labelled epididymal mouse spermatozoa. In these early experiments, we had prepared our cell suspensions from human and porcine ejaculates by a 'swim-up' method that does not completely remove seminal plasma from the cell suspension. To test whether the lack of autoradiographic labelling was due to some factor in seminal plasma that prevents binding and/or entry of foreign DNA into spermatozoa, we examined whether more complete removal of seminal plasma 
(a)

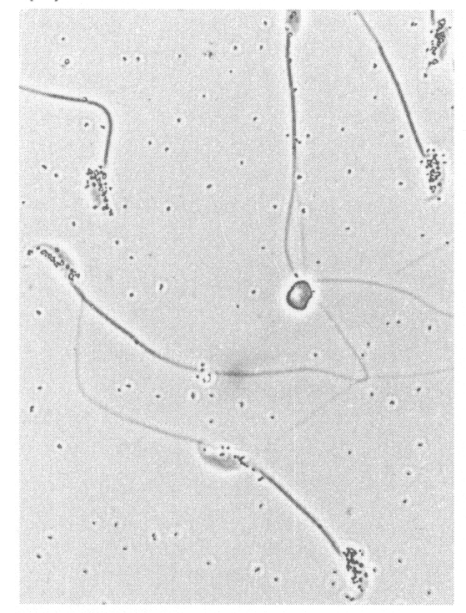

(b)

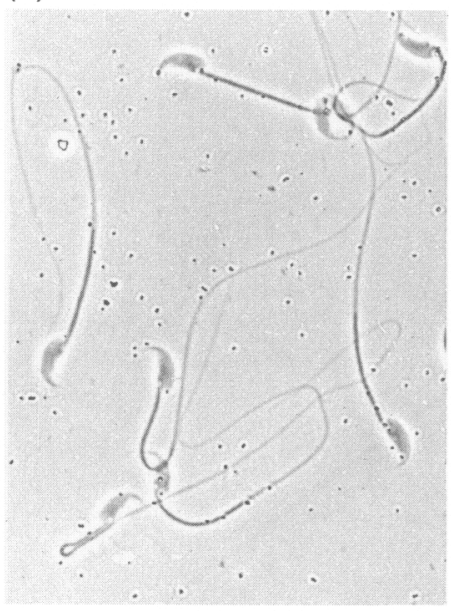

(c)

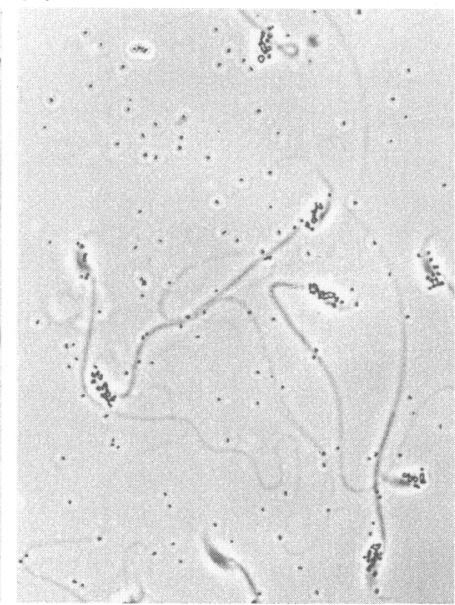

Fig. 4. Autoradiographs of (a) epididymal and (b and c) ejaculated mouse spermatozoa exposed to ${ }^{3} \mathrm{H}[\mathrm{DNA}]$. Silver grains, with a similar distribution over the sperm head, can be seen on (a) epididymal and on (c) ejaculated spermatozoa that had been washed before incubation with ${ }^{3} \mathrm{H}[\mathrm{DNA}]$. (b) Ejaculated spermatozoa exposed to DNA in the presence of diluted seminal plasma did not take up any label; $\times 600$.

would promote DNA binding by boar and human spermatozoa. The results obtained with boar spermatozoa are consistent with this hypothesis: percentage of labelled cells and labelling intensity increased greatly when the cells were accurately washed before exposure to ${ }^{3} \mathrm{H}$-DNA (Fig. 3a, b and c). With extensively washed boar spermatozoa, 70-78\% labelled cells were observed in two separate experiments. With human spermatozoa, extensive washes were not consistently followed by an increase in labelling percentage (the maximum value obtained in three experiments was $26 \%$, Fig. 3d). An additional experiment was performed, on ejaculated mouse spermatozoa, to test the hypothesis further. As expected, a suspension of ejaculated mouse spermatozoa, collected from the uterus of a recently mated female and diluted 1:20 with culture medium, did not take up any label (Fig. 4b). In contrast, if some of the cells from the same ejaculate were repeatedly washed before exposure to ${ }^{3}[\mathrm{H}] \mathrm{DNA}$, they were easily labelled (67\% labelled cells, Fig. $\left.4 \mathrm{c}\right)$. Labelling percentages of epididymal mouse spermatozoa (Fig. 4 a) were $47-52 \%$.

Ejaculated bull spermatozoa that had been obtained as frozen samples (in French straws) and had to be thoroughly washed to remove cryoprotectants always showed DNA-binding ability (39-47\% labelled cells, Fig. 3e).

\section{Kinetics of spermatozoa- ${ }^{32}$ P[DNA] association}

The kinetics of ${ }^{32} \mathrm{P}[\mathrm{DNA}]$ association with thoroughly washed ejaculated spermatozoa was similar in the three species examined (Fig. 5). Maximal uptake was observed at 20 min in human spermatozoa (Fig. 5b) and at $40 \mathrm{~min}$ in bull and boar spermatozoa (Fig. 5a and c). Longer incubations caused loss of some labelled DNA from human and porcine spermatozoa. The kinetics of ${ }^{32} \mathrm{P}[\mathrm{DNA}]$ association with mouse spermatozoa has been reported (Lavitrano et al., 1989).

The effect of a potential competitive inhibitor was assessed by measuring the association of DNA with spermatozoa that had been incubated for $30 \mathrm{~min}$ with various heparin concentrations. Preincubation with $10 \mu \mathrm{g}$ heparin $\mathrm{ml}^{-1}$ totally prevented ${ }^{32} \mathrm{P}[\mathrm{DNA}]$ association with ejaculated bull and human spermatozoa (Fig. 6a and b) and with epididymal mouse spermatozoa (Fig. 6c). 


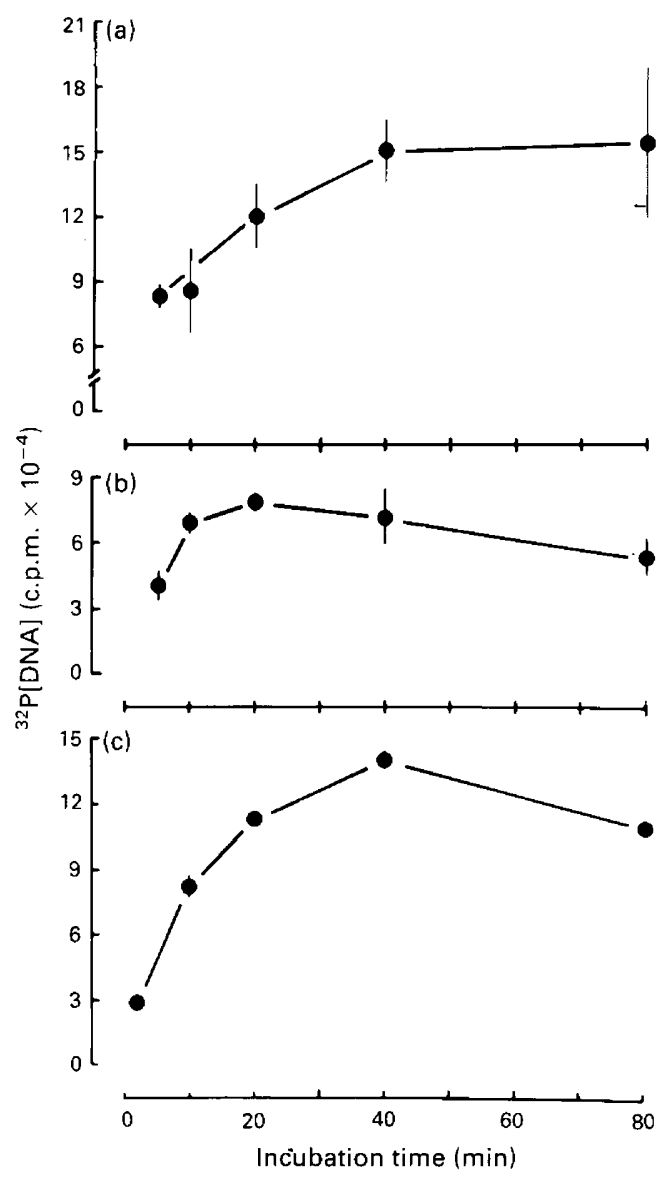

Fig. 5. Time course of the uptake of ${ }^{32} \mathrm{P}[\mathrm{DNA}]$ by (a) bull, (b) human and (c) boar ejaculated spermatozoa. The cells had been extensively washed before exposure to ${ }^{32} \mathrm{P}[\mathrm{DNA}]$.

\section{Discussion}

We performed a comparative analysis of the ability of spermatozoa from four mammalian species to bind foreign DNA. In all of them, only a limited region of the spermatozoon, the caudal half of the head (equatorial segment and postacrosomal region), appeared to have a special affinity for the ligand, as judged by autoradiographic analysis (Fig. 1). The same localization (the postacrosomal region) was observed by Brackett et al. (1971) in 30-35\% of rabbit spermatozoa that had been exposed to tritiated viral DNA. Restricted areas showing DNA-binding ability have also been identified on bovine and porcine sperm heads (Atkinson et al., 1991; Horan et al., 1991). The presence of sharply delineated regional domains, with different composition and functions is a well-known and typical feature of the spermatozoon (Holt, 1984). Such topographic heterogeneity includes marked differences between the various sperm anatomic regions in ability to bind a variety of exogenous molecules (Eddy, 1988).

Conventional autoradiographic studies do not provide detailed information on the subcellular localization of radioactive DNA molecules, information that may be of great help in evaluating the use of spermatozoa as vehicles for introducing foreign genetic material into eggs. The subcellular localization of ${ }^{3} \mathrm{H}[\mathrm{DNA}]$ bound to mouse spermatozoa was studied by high-resolution electron 


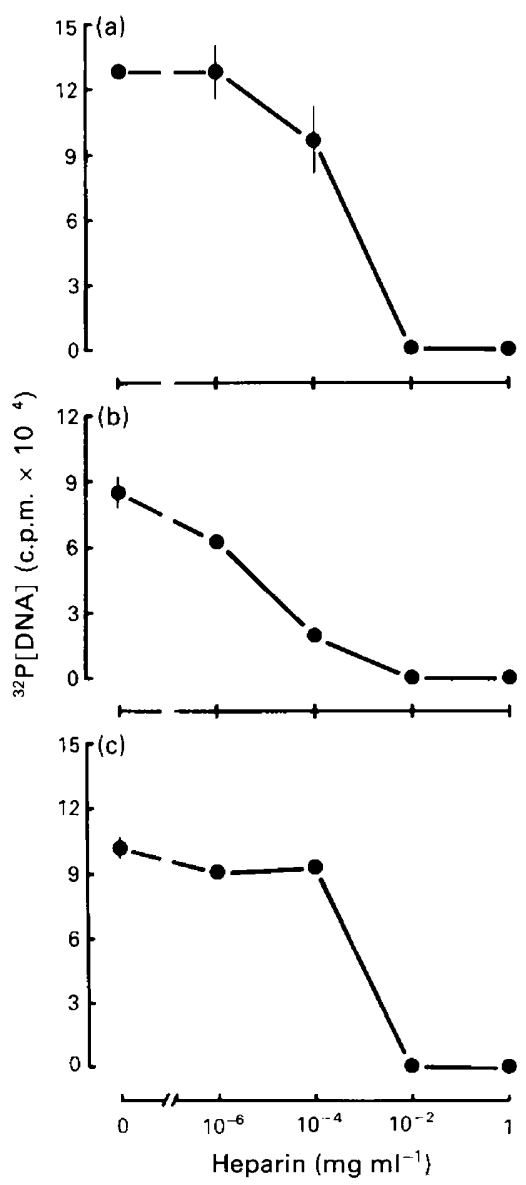

Fig. 6. Effect of increasing heparin concentration on uptake of ${ }^{32} \mathrm{P}[\mathrm{DNA}]$ by ejaculated (a) bull and (b) human and by (c) epididymal mouse spermatozoa. After incubation for $30 \mathrm{~min}$ with various heparin concentrations, ${ }^{32} \mathrm{P}[\mathrm{DNA}]$ was added, and uptake was measured $30 \mathrm{~min}$ later.

microscope autoradiography (Fig. 2). The data confirmed a preferential localization of the label over the caudal part of the sperm head. In this area, the autoradiographic grains were localized at the periphery of the cell (on the cell membrane, or possibly over the extremely thin cytoplasmatic layer beneath it); in some spermatozoa, silver grains were also clearly present over the sperm nucleus. Nuclear localization of ${ }^{3} \mathrm{H}$ [DNA] was observed in about $10 \%$ of labelled cells, i.e., by extrapolation, in about $5 \%$ of all cells.

Whereas transfer to the sperm nucleus would appear to be the obvious requirement for foreign DNA molecules to be carried into the egg at fertilization, DNA bound to the sperm surface may, in principle, be equally important in this phenomenon. Transfer of sperm-surface molecules into the egg cytoplasm has been clearly shown by immunofluorescence in fertilized sea urchin eggs (Gundersen et al., 1986). It is known that at fertilization the apical sperm membrane and the equatorial segment of the acrosome are not incorporated into the egg plasma membrane (as the rest of the sperm membrane is), but are internalized by the egg as a composite vesicle, made up of spermatozoa and egg membranes (rabbit: Bedford, 1972; hamster: Yanagimachi \& Noda, 1970; Clark \& Koehler, 1990; man: Sathananthan et al., 1986). The fate of such vesicles is unknown, but they might act as DNA carriers into the egg, not only of DNA bound to the sperm membrane, but also by entrapping DNA in solution in the culture medium. In conclusion, the available evidence 
suggests that more than one carrier mechanism might be available to the spermatozoa to introduce foreign DNA into eggs.

The potential usefulness of the sperm transfection technique depends among other things on the possibility of using readily available sperm sources. With the exception of small laboratory rodents, such as mouse, rat and hamster, for which epididymal spermatozoa are more easily obtained and more frequently used than ejaculated spermatozoa, for most other, larger mammals the reverse is true. Our early attempts to load with foreign ${ }^{3} \mathrm{H}[\mathrm{DNA}]$ boar and human ejaculated spermatozoa were, however, unsuccessful. We were only able to obtain labelled cells when we extensively washed them before exposure to DNA (Fig. $3 \mathrm{c}$ and d). Ejaculated mouse spermatozoa (collected from the uterus of a recently mated female) also required extensive washing before they could be labelled with ${ }^{3} \mathrm{H}$ [DNA] (Fig. 4b and c). The simplest explanation for these results is that factor(s) in seminal plasma may bind DNA molecules, thus making them unavailable to the spermatozoa or may compete with DNA for the same binding region on the sperm surface. Molecules that might play such roles can be tentatively identified in seminal plasma. Polyamines are basic molecules that are present in millimolar concentration in the seminal plasma of most mammalian species (Setchell \& Brooks, 1988). Their biological role has not been fully resolved, but their potential for strongly binding acidic or negatively charged molecules, such as DNA, is well documented. We have done experiments with spermine, the most abundant polyamine in seminal plasma, to see whether it would interfere with the binding of DNA to mouse spermatozoa. The results (not shown) were inconclusive, in that only partial inhibition of DNA uptake was obtained at high, unphysiological spermine concentrations.

A second seminal plasma factor that might be involved in the same surveillance function are glycosaminoglycans. These highly sulfated polymers are present in seminal plasma $\left(1.6 \mathrm{mg} \mathrm{ml}^{-1}\right.$ in cattle, Lee et al., 1985;22-44 $\mu \mathrm{g} \mathrm{ml}^{-1}$ in humans, Bürgi et al., 1990) and it has been shown that heparin can bind to human, bovine, monkey and rabbit spermatozoa in vitro (Delgado et al., 1982; Handrow et al., 1984; Hurst et al., 1988). Glycosaminoglycans in seminal plasma might interfere with the binding of foreign DNA to spermatozoa possibly by competing for the same binding sites. In our experimental conditions, the binding of DNA by ejaculated as well as epididymal spermatozoa was totally prevented by $10 \mu \mathrm{g}$ heparin $\mathrm{ml}^{-1}$ (Fig. 6).

We have shown that spermatozoa from four mammalian species can bind recombinant DNA over a specific region of the sperm head and that, at least in mice, such DNA can penetrate the sperm nucleus. Our results also suggest that factor(s) in seminal plasma might prevent potentially dangerous molecules such as foreign DNA (which may be present in the genital tracts from bacterial or viral sources) from gaining access to spermatozoa.

This work was supported by an AIRC grant to G. Siracusa, and CNR grants (Progetti Finalizzati 'FATMA' No. 92.00181.PF41 and 'BTBS') to G. Siracusa and V. M. Fazio. We thank Professor A. Lauria for helpful discussion and support.

\section{References}

Arezzo, F. (1989) Sea urchin sperm as a vector of foreign genetic information. Cell Biology International Reports 13, 391-404.

Atkinson, P.W., Hines, E.R., Beaton, S., Matthaei, K.I., Reed, K.C. \& Bradley, M.P. (1991) Association of exogenous DNA with cattle and insect spermatozoa in vitro. Molecular Reproduction and Development $\mathbf{2 9}$, $1-5$.

Avery, O.T., MacLeod, C.M. \& McCarty, M. (1944) Studies on the chemical nature of the substance inducing transformation of pneumococcal types. Journal of Experimental Medicine 83, 89-96.
Bedford, J.M. (1972) An electron microscopic study of sperm penetration into the rabbit egg after natural mating. American Journal of Anatomy 133, 213-254.

Brackett, B.G., Baranska, W., Sawicki, W. \& Koprowski, H. (1971) Uptake of heterologous genome by mammalian spermatozoa and its transfer to ova through fertilization. Proceedings of the National Academy of Sciences USA 68, 353-357.

Braude, P.R. (1987) Fertilization of human oocytes and culture of human pre-implantation embryos in vitro. In Mammalian Development: A Practical Approach, pp. 281-306. Ed. M. Monk. IRL Press, Oxford. 
Brinster, R.L., Sandgren, E.P., Behringer, R.R. \& Palmiter R.D. (1989) No simple solution for making transgenic mice. Cell 59, 239-241.

Bürgi, W., Ohishi, H., Kimura, A. \& Schmid, K. (1990) Content and distribution of glycosaminoglycans of human sperm cells and seminal fluid. Journal of Cell Biology 111, 266a.

Caro, L.G., Van Tubergen, R.P. \& Kolb, J. (1962) Highresolution autoradiography. I. Methods. Journal of Cell Biology 15, 173-188.

Clark, J.M. \& Koehler, J.K. (1990) Observations of hamster sperm-egg fusion in freeze-fracture replicas including the use of filipin as a sterol marker. Molecular Reproduction and Development 27, 351-365.

Delgado, N.M., Reyes, R., Huacuja, L., Merchant, H. \& Rosado, A. (1982) Heparin binding sites in the human spermatozoa membrane. Archives of Andrology $\mathbf{8}$, 87-95.

Eddy, E.M. (1988) The spermatozoon. In The Physiology of Reproduction, Vol. 1, pp. 27-68. Eds E. Knobil \& J. D. Neill. Raven Press, New York.

Gandolfi, F., Lavitrano, M., Camaioni, A., Spadafora, C., Siracusa, G. \& Lauria, A. (1989) The use of spermmediated gene transfer for the generation of transgenic pigs. Journal of Reproduction and Fertility Abstract Series 4, 10.

Gundersen, G.G., Medill, L. \& Shapiro, B.M. (1986) Sperm surface proteins are incorporated into the egg membrane and cytoplasm after fertilization. Developmental Biology 113, 207-217.

Handrow, R.R., Boehm, S.K., Lenz, R.W., Robinson, J.A. \& Ax, R.L. (1984) Specific binding of the glycosaminoglycan ${ }^{3} \mathrm{H}$-heparin to bovine, monkey and rabbit spermatozoa in vitro. Journal of Andrology 5, 51-63.

Hochi, S., Ninomiya, T., Mizuno, A., Honma, M. \& Yuki, A. (1990) Fate of exogenous DNA carried into mouse eggs by spermatozoa. Animal Biotechnology 1, 25-30.

Holt, W.V. (1984) Membrane heterogeneity in the mammalian spermatozoon. In International Review of Cytology, Vol. 87, pp. 159-194. Eds G. H. Bourne \& J. F. Danielli. Academic Press, New York.

Horan, R., Powell, R., McQuaid, S., Gannon, F. \& Houghton, J.A. (1991) Association of foreign DNA with porcine spermatozoa. Archives of Andrology 26, $83-92$.

Hurst, R.E., Bynum, R.L., Einfeldt, S.E. \& Johnny (1988) The identification of a heparin-binding protein on the surface of bovine sperm. Biochemical and Biophysical Research Communications 153, 289-293.

Lavitrano, M., Camaioni, A., Fazio, V.M., Dolci, S., Farace, M.G. \& Spadafora, C. (1989) Sperm cells as vectors for introducing foreign DNA into eggs. Genetic transformation of mice. Cell 57, 717-723.

Lee, C.N., Handrow, R.R., Lenz, R.W. \& Ax, R.L. (1985) Interactions of seminal plasma and glycosaminoglycans on acrosome reactions in bovine spermatozoa in vitro. Gamete Research 12, 345-355.

Parrish, J.J., Susko-Parrish, J., Winer, M.A. \& First, N.L. (1988) Capacitation of bovine sperm by heparin. Biology of Reproduction 38, 1171-1180.

Pellicer, A., Robins, D., Wold, B., Sweet, R., Jackson, J., Lowy, I., Sim, G.K., Silverstein, S. \& Axel, R. (1980) Altering genotype and phenotype by DNA-mediated gene transfer. Science 209, 1414-1422.

Perez, A., Solano, R., Castro, F.O., Leonart, R., de Armas, R., Martinez, R., Aguilar, A., Herrera, L. \& de la Fuente, J. (1991) Sperm cells mediated gene transfer in cattle. Biotecnologia Aplicada 8, 90-94.

Rogers, A.W. (1973) Techniques of Autoradiography (2nd edn). Elsevier Science Publishers, New York.

Sathananthan, A.H., Ng, S.C., Edirisinghe, R., Ratnam, S.S. \& Wong, P.C. (1986) Human sperm-egg interaction in vitro. Gamete Research 15, 317-326.

Setchell, B.P. \& Brooks, D.E. (1988) Anatomy, vasculature, innervation and fluids of the male reproductive tract. In The Physiology of Reproduction, Vol. 1, pp. 753-836. Eds E. Knobil \& J. D. Neill. Raven Press, New York.

Whittingham, D.G. (1968) Fertilization of mouse eggs in vitro. Nature 220, 592-593.

Yanagimachi, R. \& Noda, T.D. (1970) Electron microscope studies of sperm incorporation into the golden hamster egg. American Journal of Anatomy 128, $429-462$.

Received 5 August 1991 